\title{
DUS Characterization of some Released Varieties and Advanced Breeding Lines of Soybean (Glycine max L.) under Punjab Agroclimatic Conditions
}

\author{
I. Dhaliwal $^{1^{*}}$, G. Khosla ${ }^{2}$, T.P. Singh ${ }^{2}$, B.S. Gill ${ }^{1}$ and P. Kaushik ${ }^{3}$ \\ ${ }^{1}$ Department of Plant Breeding and Genetics, Punjab Agricultural University, \\ Ludhiana-141004, India \\ ${ }^{2}$ DirectorSeeds, Punjab Agricultural University, Ludhiana-141004, India \\ ${ }^{3}$ Instituto de Conservación y Mejora de la Agrodiversidad Valenciana, Universitat Politècnica \\ de València, Valencia 46022, Spain \\ *Corresponding author
}

\section{A B S T R A C T}

Soybean is ranked as one of the major oil crops in the world. In India, the consumption of soybean oil, as well as other soy-based products, has been on the rise which has led to its occupying a cherished position in area and production amongst the different oilseed crops.

\section{Keywords}

Characterization, DUS, Soybean, Morphological

Article Info

\section{Accepted:}

20 July 2020

Available Online:

10 August 2020 Morphological characterization of genotypes helps create a database on the grounds of which these can be distinguished and the genetic diversity existing in them can be assessed. A total of 22 soybean lines were evaluated for DUS characterization, which comprised of 7 released varieties and 15 advanced breeding lines bred under Punjab agroclimatic conditions. Of the 19 characters observed only one character, viz, plant growth type, was monomorphic and showed no variation amongst any of the lines studied. All the entries exhibited semi-determinate growth type during both the years of observation. Nine characters were dimorphic while 9 characters showed polymorphic variation. The study revealed that flower color and hypocotyl pigmentation could be used as critical morphological characters for ascertaining varietal distinctiveness amongst genotypes. Of the 22 genotypes, few were utterly unique as they could be distinguished based on a single trait while the majority were very closely related. Cluster analysis revealed that the 22 genotypes could be grouped into four major clusters, whereby 13 genotypes were found to be unique based on at least one character and others could be distinguished based on a set of traits rather than a single trait.

\section{Introduction}

DUS (Distinctness, Uniformity and Stability) testing is critical for an appropriate varietal registration under Plant Varieties and Farmers Right Act (PPV\&FRA), 2001. Morphological characterization of genotypes helps create a database on the grounds of which these can be distinguished and the genetic diversity existing in them can be assessed. Varietal characterization is thus an effective means to identify and avoid duplication (Das and Kumar, 2012). Qualitative characters are more dependable for germplasm 
characterization since they behave stably over environments and generations (Raut, 2003). Such characterization further proves useful for identification of suitable lines to be released as commercial varieties for a particular agro-climatic zone (Moukoumbi et al., 2011). The sequential use of morphological descriptors is hence effective in distinguishing different types. Moreover, soybean is a good candidate for the biofortification of minerals and other useful phytochemicals as in wheat and rice (Kaushik et al., 2018; Saini et al., 2019; Sharma et al., 2020).

Soybean (Glycine max (L.) Merrill), an economically crucial diploid legume $(2 \mathrm{n}=$ 40 ), is ranked as one of the major oil crops in the world (Chung and Singh 2008). The seeds have an average of $40 \%$ protein, and $20 \%$ oil, as well as the soybean roots enrich the soil through symbiotic nitrogen fixation.

In India, the consumption of soybean oil and other soy-based products has been on the rise as a result of the surge in population and ascent in living standards of people. This has led to its occupying a cherished position in area and production amongst the different oilseed crops in the country. However, there is an issue of low productivity in the crop which is attributed to both genetic and nongenetic factors like susceptibility to biotic and abiotic stresses (Dupare et al., 2010; Saahu et al., 2013).

These issues can be well addressed through the genetic improvement of this crop by understanding the genetic diversity, variability, its nature and magnitude as well as character association studies which would help in formulating a suitable selection criterion for different traits to gain higher productivity. Thus, a database created through morphological characterization of genotypes would help distinguish them as well as help assess the genetic diversity existing in them (Raut, 2003). With this background, the present study was planned to evaluate some advanced breeding lines and released varieties of soybean bred under Punjab agroclimatic conditions for various qualitative traits as per the National guidelines for the conduct of DUS test on Soybean (Anonymous, 2009).

\section{Materials and Methods}

A total of 22 soybean lines were evaluated for DUS characterization, which comprised of 7released varietiesand15advanced breeding lines bred under Punjab agroclimatic conditions for cultivation in the Punjab state (Table 1). The soil belonged to the sandy loam class (Kaushik, 2020). The material was raised in a Randomized Complete Block Design with three replications during the Kharif season of 2016 and 2017 at the Soybean Experimental Research Farm, Punjab Agricultural University, Ludhiana.

Each line was sown in a 13.5 sqmplot, where each plot had 6 rows of 5-meter length. The rows were spaced $45 \mathrm{~cm}$ apart, and plants in each row were spaced $10 \mathrm{~cm}$ apart. The crop was raised following the recommended package and practices for Punjab. The data were recorded for 19 simply observable and stable morphological characters (Table 2) as per DUS test guidelines for soybean. For characters that required data to be recorded on an individual plant basis, 5 plants were tagged from the plot, excluding border rows, and then the average was worked out.

\section{Data analysis}

All statistical analysis was performed employing the Statgraphics Centurion XVI software (StatPoint Technologies, Warrenton, VA, USA). Further, the Pearson coefficients of correlation (r) were estimated and plotted using the package Corrplot. 


\section{Results and Discussion}

\section{Distinctness based on morphological traits}

Based on the test of distinctiveness using visual scoring, of the 19 characters observed (Table 3), only one character, viz., plant growth type, was monomorphic and showed no variation amongst any of the lines studied. All the entries exhibited semi-determinate growth type during both the years of observation. Nine characters were dimorphic while 9 characters showed polymorphic variation.

The study revealed that flower color and hypocotyl pigmentation could be used as important morphological characters for ascertaining varietal distinctiveness amongst genotypes. Presence of hypocotyl anthocyanin pigmentation was correlated with violet flower colour. All the genotypes, except SL 900 and SL 688, bore white colored flowers; both SL 900 and SL 688 bore violet coloured flowers and exhibited the presence of strong anthocyanin pigmentation. Hypocotyl pigmentation was absent in all but two (SL 1123 and SL 1171) white-flowered genotypes.

All the genotypes displayed semi-erect type growth habit, except SL 1113 that had erect to semi-erect type growth habit. Majority of the genotypes had tawny-coloured hair on the stem whereas SL 1171, SL 1119, SL 1104, SL 525 and SL 1113 had grey coloured hair. A perusal of the data for plant height revealed that majority of the genotypes were medium statured. SL 900 is a high statured line whereas SL 688 and SL 1193 are short to medium statured.

Fourleaf traits, viz., leaf blistering, the shape of lateral leaflets, size of lateral leaflets and leaf colour intensity were recorded. Leaf blistering was observed to be a polymorphic trait. None of the genotypes exhibited very strong leaf blistering; all the other four designated classes of leaf blistering were found in the genotypes studied. Blistering was absent or was very weak in six genotypes, feeble (weak) in six genotypes, medium in seven genotypes and strong in three genotypes. Three of the four designated classes of the shape of lateral leaflets were recorded in the genotypes under study. SL 688 was the only genotype that bore rounded ovate lateral leaflets. SL 1119, SL 1191, SL 1193 and SL 525 had triangular leaflets while the rest of the genotypes had pointed ovate leaflets. Size of the lateral leaflets is another important leaf trait that distinguished SL 900 (large leaflet) from the rest of the genotypes; it has medium-sized lateral leaflets. SL 744, which bore light green coloured leaves, and SL 688 and SL 1200, which bore dark green leaves were found to be distinct from rest of the genotypes on the basis of leaf colour intensity. All the other genotypes had a medium intensity of green colour on leaves.

Only one pod trait, i.e., the intensity of brown colour on pods was included in this study. Two genotypes, viz., SL 525 and SL 744 had medium intensity and were distinct from other genotypes having light colour (8 genotypes) and dark colour (12 genotypes) pods. Seed traits are also crucial for DUS characterization as these are less affected by the environment and are thus more stable. Six seed traits were studied in the present investigation. Seed size was computed on the basis of 100 seed weight. As all the genotypes in the present study were of grain type, therefore, only two classes of seed size, viz., small and medium, were observed. Maximum number of genotypes (16) had medium-sized seeds; all but one (SL 1171) had spherical shaped seeds while SL 1171had flattened spherical seeds. Seed hilum colour is also a highly stable and polymorphic trait. In the present study too, five out of six designated classes of hilum colour were observed. SL 1113 was the only genotype with grey hilum, 
whereas SL 1180 and SL 1191 had imperfect black hilum. Apart from this, 8 genotypes had light brown, 6 genotypes had dark brown, and 5 genotypes had black hilum. Most of the genotypes (15) had different funicle colour than that of hilum while 7 genotypes had the same funicle colour as that of the hilum.

SL 900 was the only genotype that flowered late (72days) while SL 955 exhibited medium to late flowering (68 days). All other genotypes had medium flowering time (60-65 days). Similarly, based on days to maturity, three genotypes, viz., SL 688 (early to medium maturity; 124 days), SL 1193 (medium maturity; 127 days) and SL 1235 (late maturity; 137 days) were found to be distinct from the rest of the genotypes as these had medium to late maturity (130-136 days).

\section{Cluster analysis for distinctiveness}

Of the 22 genotypes, few were unique as they could be distinguished based on a single trait while majority were very closely related. Based on the cluster analysis, the 22 genotypes were grouped into four major clusters (Figure 1). The first cluster has 18 genotypes that were subdivided further into 2twosub clusters (Figure 1). The first sub cluster has 6 genotypes, viz., SL 1068, SL 1235, SL 955, SL 1233, SL 744 and SL 1119. SL 1068, SL 1235 and SL 955 are very similar to each other with respect to all but one character each (Table 3); SL 955 differs from the rest two for days to $50 \%$ flowering and SL 1235 differs with respect to time to maturity. These genotypes are hence closely placed.

SL 1233 and SL 744 are different from the aforementioned genotypes concerning two traits each, viz., ground color of testa and colour of hilum funicle (SL 1233) and intensity of green colour leaves and intensity of brown colour pods (SL 744). SL 1119 differs with respect to 4 traits from all the other five genotypes (color of hair on main stem, shape of lateral leaflet, intensity of brown color on pods and colour of hilum funicle) and hence has a clear distinct lineage in this cluster (Figure 1).

In the second sub cluster of cluster 1 , there were twelve genotypes, viz., SL 1104, SL 958, SL 1200, SL 1234, SL 1154, SL 1202, SL 1180, SL 979, SL 525, SL 1191, SL 1193 and SL 1123. Majority of the genotypes differed from each other with respect to two traits, viz., presence of leaf blistering and color of hilum funicle (Table 3 ).

In addition, SL 1123 exhibited weak anthocyanin pigmentation on the hypocotyle and thus bore white colored flowers; SL 1193 differed for plant height, shape of lateral leaflet and time to maturity; SL 525 differed for color of hair on the main stem, shape of lateral leaflet and intensity of brown color on pods; SL 1191 differed for plant height and shape of the lateral leaflet; SL 1200 differed for the intensity of green color on leaves; SL 1104 differed for color of hair on main stem. The following genotypes were found to be very close to each other: SL 1068 to SL 1235; Sl 1233 to SL 744; SL 1104 to SL 958; SL 1154 to SL 1202; SL 1180 to SL 979; and, SL 525 to SL 1191.

The second cluster had two genotypes, viz., SL 1113 and SL 1171. Both differed from each other with respect to presence of weak hypocotyl anthocyanin coloration, plant growth habit, leaf blistering and seed shape. SL 1113 was unique for growth habit whereas SL 1171 has spherical flattened seed shape.SL 688 belonged to the third cluster, and SL 900 belonged to the fourth cluster. SL 688 and SL 900 were the only genotypes that exhibited strong hypocotyl anthocyanin pigmentation and bore purple flowers. These two genotypes are unique as they differ from the rest of the genotypes concerning 12 traits (Table 3). 
Correlations amongst the different traits studied

The Pearson's correlation coefficients were worked out amongst the different traits under study, and it was found that there were 23 significant correlations amongst the different traits (Figure 2). Of these significantly strong positive correlations $(\mathrm{p}=<0.05)$ were observed for 17 of the trait combinations and significantly strong negative associations $(\mathrm{p}=$ $<0.05$ ) were followed for 6 trait combinations. Amongst the several trait correlations (Figure 2), hypocotyl coloration was strongly correlated with flower color, which was also evident in the morphological observations.

Table.1 The 7 released varieties and 15 advanced breeding lines of soybean evaluated for DUS characterisation

\begin{tabular}{|l|l|}
\hline \multicolumn{2}{|c|}{$\begin{array}{l}\text { Sr. No. } \\
\text { Released varieties }\end{array}$} \\
\hline $\mathbf{1}$ & SL525 \\
\hline $\mathbf{2}$ & SL 688 \\
\hline $\mathbf{3}$ & SL 744 \\
\hline $\mathbf{4}$ & SL 955 \\
\hline $\mathbf{5}$ & SL 958 \\
\hline $\mathbf{6}$ & SL 979 \\
\hline $\mathbf{7}$ & SL 1104 \\
\hline \multicolumn{1}{|c|}{ Advanced breeding lines } \\
\hline $\mathbf{8}$ & SL900 \\
\hline $\mathbf{9}$ & SL1068 \\
\hline $\mathbf{1 0}$ & SL1113 \\
\hline $\mathbf{1 1}$ & SL 1119 \\
\hline $\mathbf{1 2}$ & SL1123 \\
\hline $\mathbf{1 3}$ & SL1154 \\
\hline $\mathbf{1 4}$ & SL 1171 \\
\hline $\mathbf{1 5}$ & SL1180 \\
\hline $\mathbf{1 6}$ & SL1191 \\
\hline $\mathbf{1 7}$ & SL1193 \\
\hline $\mathbf{1 8}$ & SL1200 \\
\hline $\mathbf{1 9}$ & SL 1202 \\
\hline $\mathbf{2 0}$ & SL1233 \\
\hline $\mathbf{2 1}$ & SL1234 \\
\hline $\mathbf{2 2}$ & SL 1235 \\
\hline & \\
\hline
\end{tabular}


Table.2 The 19 morphological characters recorded as per DUS test guidelines for soybean

\begin{tabular}{|c|c|c|c|}
\hline Sr. No. & Characteristic & Stage & Note \\
\hline 1. & $\begin{array}{l}\text { Hypocotyl: anthocyanin } \\
\text { coloration }\end{array}$ & $\begin{array}{l}\text { Absent } \\
\text { present }\end{array}$ & $\begin{array}{l}1 \\
9\end{array}$ \\
\hline 2. & $\begin{array}{l}\text { Hypocotyl: intensityof } \\
\text { anthocyanincoloration }\end{array}$ & $\begin{array}{l}\text { very weak } \\
\text { weak } \\
\text { medium } \\
\text { strong } \\
\text { very strong }\end{array}$ & $\begin{array}{l}1 \\
3 \\
5 \\
7 \\
9\end{array}$ \\
\hline 3. & Plant: growth type & $\begin{array}{l}\text { determinate } \\
\text { semi-determinate } \\
\text { semi-determinate to } \\
\text { indeterminate } \\
\text { indeterminate }\end{array}$ & $\begin{array}{l}1 \\
2 \\
3 \\
4\end{array}$ \\
\hline 4. & Plant: growthhabit & $\begin{array}{l}\text { erect } \\
\text { erect to semi-erect } \\
\text { semi-erect } \\
\text { semi-erect to horizontal } \\
\text { horizontal }\end{array}$ & $\begin{array}{l}1 \\
2 \\
3 \\
4 \\
5\end{array}$ \\
\hline 5. & $\begin{array}{l}\text { Plant: color of hairs of } \\
\text { main stem } \\
\text { (on middle third) }\end{array}$ & $\begin{array}{l}\text { grey } \\
\text { tawny }\end{array}$ & $\begin{array}{l}1 \\
2\end{array}$ \\
\hline 6. & Plant: height & $\begin{array}{l}\text { short } \\
\text { short to medium } \\
\text { medium } \\
\text { medium to tall } \\
\text { tall }\end{array}$ & $\begin{array}{l}3 \\
4 \\
5 \\
6 \\
7\end{array}$ \\
\hline 7. & Leaf: blistering & $\begin{array}{l}\text { absent or very weak } \\
\text { weak } \\
\text { medium } \\
\text { strong } \\
\text { very strong }\end{array}$ & $\begin{array}{l}1 \\
3 \\
5 \\
7 \\
9\end{array}$ \\
\hline 8. & Leaf: shape oflateral leaflet & $\begin{array}{l}\text { Lanceolate } \\
\text { triangular } \\
\text { pointed ovate } \\
\text { rounded ovate }\end{array}$ & $\begin{array}{l}1 \\
2 \\
3 \\
4\end{array}$ \\
\hline 9. & Leaf: size of lateral leaflet & $\begin{array}{l}\text { small } \\
\text { medium } \\
\text { large }\end{array}$ & $\begin{array}{l}3 \\
5 \\
7\end{array}$ \\
\hline 10. & $\begin{array}{l}\text { Leaf: intensity of green } \\
\text { color }\end{array}$ & $\begin{array}{l}\text { Light } \\
\text { medium } \\
\text { dark }\end{array}$ & $\begin{array}{l}3 \\
5 \\
7\end{array}$ \\
\hline 11. & Flower: color & $\begin{array}{l}\text { white } \\
\text { violet }\end{array}$ & $\begin{array}{l}1 \\
2\end{array}$ \\
\hline
\end{tabular}




\begin{tabular}{|c|c|c|c|}
\hline 12. & $\begin{array}{l}\text { Pod: intensity of brown } \\
\text { color }\end{array}$ & $\begin{array}{l}\text { light } \\
\text { medium } \\
\text { dark }\end{array}$ & $\begin{array}{l}3 \\
5 \\
7\end{array}$ \\
\hline 13. & Seed: size & $\begin{array}{l}\text { small } \\
\text { medium } \\
\text { large }\end{array}$ & $\begin{array}{l}3 \\
5 \\
7\end{array}$ \\
\hline 14. & Seed: shape & $\begin{array}{l}\text { spherical } \\
\text { spherical flattened } \\
\text { elongated } \\
\text { elongated flattened }\end{array}$ & $\begin{array}{l}1 \\
2 \\
3 \\
4\end{array}$ \\
\hline 15. & $\begin{array}{l}\text { Seed: ground color of testa } \\
\text { (excluding hilum) }\end{array}$ & $\begin{array}{l}\text { yellow } \\
\text { yellow green } \\
\text { green } \\
\text { light brown } \\
\text { medium brown } \\
\text { dark brown } \\
\text { black }\end{array}$ & $\begin{array}{l}1 \\
2 \\
3 \\
4 \\
5 \\
6 \\
7\end{array}$ \\
\hline 16. & Seed: hilum color & $\begin{array}{l}\text { grey } \\
\text { yellow } \\
\text { light brown } \\
\text { dark brown }\end{array}$ & $\begin{array}{l}1 \\
2 \\
3 \\
4\end{array}$ \\
\hline & & $\begin{array}{l}\text { imperfect black } \\
\text { black }\end{array}$ & $\begin{array}{l}5 \\
6\end{array}$ \\
\hline 17. & Seed: color of hilum funicle & $\begin{array}{l}\text { same as testa } \\
\text { different to testa }\end{array}$ & $\begin{array}{l}1 \\
2\end{array}$ \\
\hline 18. & $\begin{array}{l}\text { Plant: time of beginning of } \\
\text { flowering } \\
\text { (50\% plants with at least } \\
\text { one flower open) }\end{array}$ & $\begin{array}{l}\text { very early } \\
\text { very early to early } \\
\text { early } \\
\text { early to medium } \\
\text { medium } \\
\text { medium to late } \\
\text { late } \\
\text { late to very late } \\
\text { very late }\end{array}$ & $\begin{array}{l}1 \\
2 \\
3 \\
4 \\
5 \\
6 \\
7 \\
8 \\
9\end{array}$ \\
\hline 19. & Plant: time of maturity & $\begin{array}{l}\text { very early } \\
\text { very early to early } \\
\text { early } \\
\text { early to medium } \\
\text { medium } \\
\text { medium to late } \\
\text { late } \\
\text { late to very late } \\
\text { very late }\end{array}$ & $\begin{array}{l}1 \\
2 \\
3 \\
4 \\
5 \\
6 \\
7 \\
8 \\
9\end{array}$ \\
\hline
\end{tabular}


Table. 3 Characterization of the 22 soybean genotypes under study as per DUS test guidelines

\begin{tabular}{|c|c|c|c|c|c|c|c|c|c|c|c|c|c|c|c|c|c|c|c|}
\hline \multirow[t]{2}{*}{ Genotype } & \multicolumn{19}{|c|}{ Traits* } \\
\hline & 1 & 2 & 3 & 4 & 5 & 6 & 7 & 8 & 9 & 10 & 11 & 12 & 13 & 14 & 15 & 16 & 17 & 18 & 19 \\
\hline SL 1068 & 1 & - & 2 & 3 & 2 & 5 & 1 & 3 & 5 & 5 & 1 & 3 & 3 & 1 & 2 & 3 & 2 & 5 & 6 \\
\hline SL 1104 & 1 & - & 2 & 3 & 1 & 5 & 1 & 3 & 5 & 5 & 1 & 7 & 5 & 1 & 1 & 3 & 1 & 5 & 6 \\
\hline SL 1113 & 1 & - & 2 & 2 & 1 & 5 & 1 & 3 & 5 & 5 & 1 & 3 & 5 & 1 & 1 & 6 & 2 & 5 & 6 \\
\hline SL 1119 & 1 & - & 2 & 3 & 1 & 5 & 5 & 2 & 5 & 5 & 1 & 7 & 3 & 1 & 2 & 1 & 1 & 5 & 6 \\
\hline SL 1171 & 9 & 3 & 2 & 3 & 1 & 5 & 3 & 3 & 5 & 5 & 1 & 3 & 5 & 2 & 1 & 6 & 2 & 5 & 6 \\
\hline SL 1233 & 1 & - & 2 & 3 & 2 & 5 & 5 & 3 & 5 & 5 & 1 & 3 & 3 & 1 & 1 & 4 & 1 & 5 & 6 \\
\hline SL 1234 & 1 & - & 2 & 3 & 2 & 5 & 3 & 3 & 5 & 5 & 1 & 7 & 5 & 1 & 2 & 3 & 1 & 5 & 6 \\
\hline SL 958 & 1 & - & 2 & 3 & 2 & 5 & 1 & 3 & 5 & 5 & 1 & 7 & 5 & 1 & 1 & 6 & 1 & 5 & 6 \\
\hline SL 688 & 9 & 5 & 2 & 3 & 2 & 4 & 7 & 4 & 5 & 7 & 2 & 3 & 5 & 1 & 1 & 3 & 2 & 5 & 4 \\
\hline SL 525 & 1 & - & 2 & 3 & 1 & 5 & 7 & 2 & 5 & 5 & 1 & 5 & 5 & 1 & 2 & 6 & 2 & 5 & 6 \\
\hline SL 744 & 1 & - & 2 & 3 & 2 & 5 & 7 & 3 & 5 & 3 & 1 & 5 & 3 & 1 & 2 & 4 & 2 & 5 & 6 \\
\hline SL 1123 & 9 & 5 & 2 & 3 & 2 & 5 & 1 & 3 & 5 & 5 & 1 & 7 & 5 & 1 & 2 & 3 & 2 & 5 & 6 \\
\hline SL 1154 & 1 & - & 2 & 3 & 2 & 5 & 5 & 3 & 5 & 5 & 1 & 7 & 5 & 1 & 2 & 4 & 2 & 5 & 6 \\
\hline SL 1180 & 1 & - & 2 & 3 & 2 & 5 & 5 & 3 & 5 & 5 & 1 & 7 & 5 & 1 & 1 & 5 & 2 & 5 & 6 \\
\hline SL 1191 & 1 & - & 2 & 3 & 2 & 6 & 3 & 2 & 5 & 5 & 1 & 7 & 5 & 1 & 2 & 5 & 2 & 5 & 6 \\
\hline SL 1193 & 1 & - & 2 & 3 & 2 & 4 & 5 & 2 & 5 & 5 & 1 & 7 & 5 & 1 & 2 & 4 & 2 & 5 & 5 \\
\hline SL 1200 & 1 & - & 2 & 3 & 2 & 5 & 3 & 3 & 5 & 7 & 1 & 7 & 5 & 1 & 1 & 3 & 1 & 5 & 6 \\
\hline SL 1202 & 1 & - & 2 & 3 & 2 & 5 & 3 & 3 & 5 & 5 & 1 & 7 & 5 & 1 & 2 & 3 & 2 & 5 & 6 \\
\hline SL 1235 & 1 & - & 2 & 3 & 2 & 5 & 1 & 3 & 5 & 5 & 1 & 3 & 3 & 1 & 2 & 4 & 2 & 5 & 7 \\
\hline SL 979 & 1 & - & 2 & 3 & 2 & 5 & 5 & 3 & 5 & 5 & 1 & 7 & 5 & 1 & 2 & 6 & 2 & 5 & 6 \\
\hline SL 955 & 1 & - & 2 & 3 & 2 & 5 & 3 & 3 & 5 & 5 & 1 & 3 & 3 & 1 & 2 & 3 & 2 & 6 & 6 \\
\hline SL 900 & 9 & 7 & 2 & 3 & 2 & 7 & 5 & 3 & 7 & 5 & 2 & 3 & 5 & 1 & 2 & 4 & 1 & 7 & 6 \\
\hline
\end{tabular}


Figure.1 Cluster dendrogram of the 22 soybean genotypes based on 19 DUS characteristics recorded over 2 years.

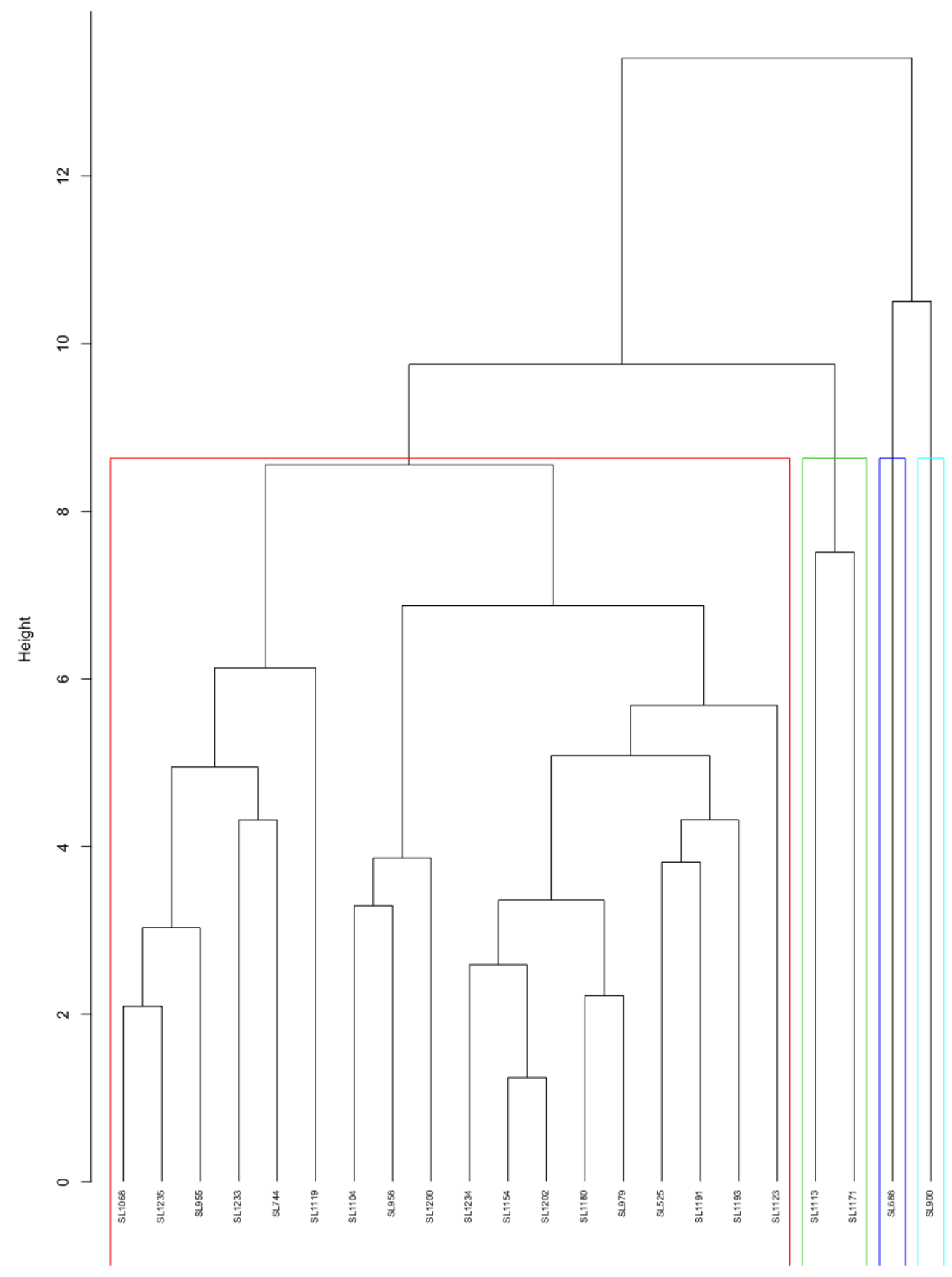


Figure.2 Heat map of the 19 DUS characteristics based on the Pearson's correlation coefficients amongst them. The darker the square the stronger is the correlation. The values in the boxes indicate the correlation between the two traits. Purple color represents positive correlation and brown color represents negative correlation

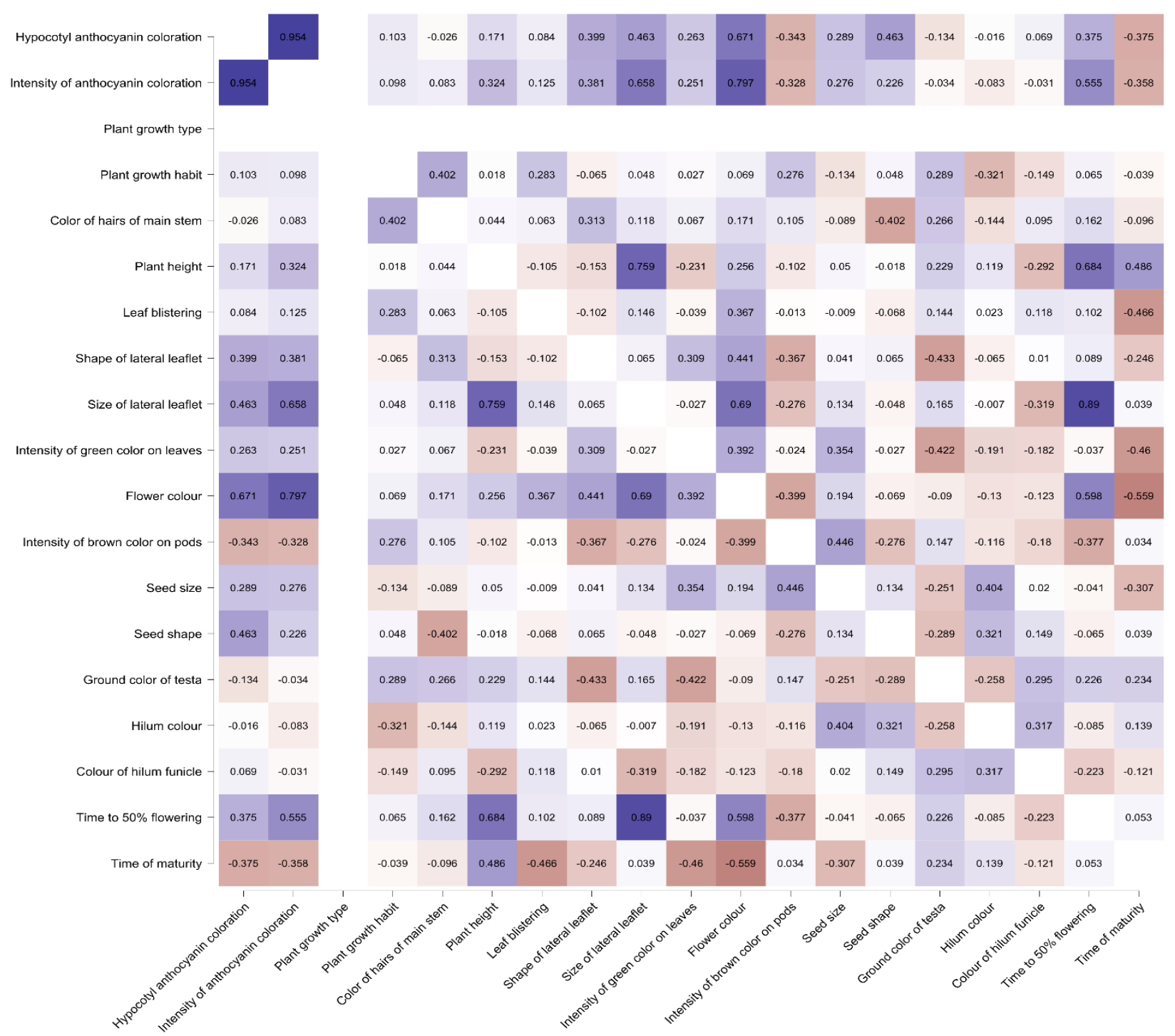

The impact of environmental fluctuations on qualitative characters is less pronounced and these are therefore employed as the most credible phenotypic markers for differentiating species and varieties. In soybean, the published literature also corroborates these assertions; the characters such as flower colour, presence/absence of pod hair, colour of hair and seed colour were found to be the most stable across various agro-climatic zones of India (Satyavathi et al., 2004, Gupta et al., 2010). From the present study, it is deduced that of the 22 genotypes studied, 13 were found to be unique based on at least one character. Others could be distinguished on the basis of a set of traits rather than a single trait. Gupta et al., (2010) and Ramteke and Murlidharan (2012) have 
also reported that white-flowered genotypes exhibit no hypocotyl anthocyanin pigmentation, whereas the pigmentation is present in violet flowered genotypes. On the basis of their findings, Ramteke and Murlidharan (2012) grouped soybean varieties of India into two major groups with respect to flower colour; i.e., white flowered and violet flowered. However, Payne and Sundermeyer (1977) observed hypocotyl pigmentation in a few white-flowered soybean genotypes, as were found in our investigation. This is also supported by the high correlation coefficients between these two traits found in the present study (Kumar and Kaushik 2020; Kumar et al., 2018).

Morris and Payne (1977) have suggested seed traits such as seed size, seed coat colour and hilum colour to distinguish different soybean varieties. Majority of the grain type soybeans have small and medium-sized seeds. Large seeds are conventional in vegetable type soybean. As all the genotypes in the present study were of grain type, therefore, only two classes of seed size, viz., small and medium, were observed. Maximum number of genotypes (16) had medium-sized seeds; because seed size is highly correlated with yield, therefore breeders generally tend to select medium/bold seeded genotypes. Selection for seed shape is also based on consumer preference. Generally, for table purpose, spherical seeds are preferred over other shapes. Seed hilum colour is also a highly stable and polymorphic trait. In the present study too, hilum colour was the most polymorphic trait and was found to be important along with flower colour and hypocotyl anthocyanin pigmentation; five out of six designated classes of hilum colour were observed.

Plant growth type was the only monomorphic trait in the present study as all the genotypes were of semi determinate type. However, Karnwal and Singh (2009) recorded a span of
$66.25-110.75 \mathrm{~cm}$ for soybean genotypes that they characterised.

Hence concluded, for identifying a variety, all the traits should be considered collectively. Additionally, biochemical markers and molecular markers can be employed for total distinction of varieties. In this context, DNA fingerprinting is also of utmost importance. From the present investigation, of the 22 genotypes studied, 13 were found to be unique based on at least one character. Other could be distinguished on the basis of a set of traits rather than a single trait. The present study will be beneficial to breeders and researchers for identification of variable sources so as to be used in further breeding programs and thus seek protection under Protection of Plant Varieties and Farmers Rights Act.

\section{References}

Anonymous. (2009): Guidelines for the conduct of test for distinctiveness, uniformity and stability on soybean (Glycine max (L.) Merril). - Plant Variety Journal of India 3: 13-22.

Chung, G., Singh, R.J. (2008): Broadening the genetic base of soybean: A multidisciplinary approach. - Critical Reviews in Plant Science 27: 295-341.

Das, A., Kumar, D. (2012): Genetic evaluation and characterization of jute (Corchorus spp. L) genotypes using DUS parameters. - SAARC Journal of Agriculture 10: 147153.

Dupare, B.U., Billore, S.D., Joshi, O.P. (2010): Farmers' problems associated with cultivation of soybean in Madhya Pradesh. - Indian Journal of Agricultural Science and Technology 4: 71-78.

Gupta, A., Mahajan, V., Khati, P., Srivastava, A.K. (2010): Distinctness in Indian soybean (Glycine max) varieties using DUS characters. - Indian Journal of Agricultural Sciences. 80:1081-4.

Karnwal, M.K., Singh, K. (2009): Studies on 
genetic variability, character association and path coefficient for seed yield and its contributing traits in soybean [Glycine $\max ($ L.) Merrill]. - Legume Research 32(1): 70-3.

Kumar, P., Kaushik, P. (2020). Evaluation of Genetic Diversity in Cultivated and Exotic Germplasm Sources of Faba Bean Using Important Morphological Traits. BioRxiv.

Kumar, P., Bishnoi, S., Kaushik, P., 2018. Genetic Variability, Heritability and Genetic Advance for Seed Yield and Other Agro-Morphological Traits in Fababean (Vicia faba L.) Genotypes of Different Origin. Trends in Biosciences 10(4): 1246-1248.

Kaushik, P., Dhaliwal, M.S., Kumar, S., 2018. Usefulness of Three under Exploited Vegetable Legumes-A Review. Int. J. Curr. Microbiol. Appl. Sci 7, 861-870.

Kaushik, P. (2020). Classification of Indian States and Union Territories based on their Soil Macronutrient and Organic Carbon Profiles. bioRxiv 2020.02.10.930586. https://doi.org/10.1101/2020.02.10.93058 6

Morris, L.F., Payne, R.C. (1977): Phenotypic characteristics of 116 soybean varieties. AOSA Newsletter 51: 43-50.

Moukoumbi, Y.D., Sie, M., Vodouhe, R., Ndri, B., Toulou, B., Ogunbayo, S.A., Ahanchede, A. (2011): Assessing phenotypic diversity of interspecific rice varieties using agro-morphological characterization. - Journal of Plant Breeding and Crop Science 3: 74-86.

Payne, R.C., Sundermeyer, E.W. (1977): Pigmentation differences of soybean with green hypocotyl color when grown in continuous light. - Crop Science 19: 1246.

Ramteke, R., Kumar, V., Murlidharan, P., Agarwal, D.K. (2010): Study on genetic variability and traits interrelationship among released soybean varieties of India [Glycine $\max (\mathrm{L}$.$) Merrill]. - Electronic$ Journal of Plant Breeding 1(6): 1483-7.

Ramteke, R., Murlidharan, P. (2012): Characterization of soybean (Glycine max) varieties as per DUS guidelines. Indian Journal of Agricultural Sciences $82: 572-577$

Raut, V.M. (2003): Qualitative genetics of soybean- a review. - Soybean Research 1: 1-28.

Saahu, A., Bello, L., Vange, T. (2013): Correlation, path coefficient and principal component analysis of seed yield in soybean genotypes. - International Journal of Advanced Research 1: 1-5.

Saini, D.K., Devi, P., Kaushik, P., 2020. Advances in Genomic Interventions for Wheat Biofortification: A Review. Agronomy 10, 62.

Sharma, V., Kumar Saini, D., Kumar, A., Kesh, H., Kaushik, P., 2020. Breeding for Biofortification Traits in Rice: Means to Eradicate Hidden Hunger, in: Amanullah (Ed.), Agronomy - Climate Change and Food Security. Intech Open.

Satyavathi, C.T., Bharadwaj, C.H., Husain, S.M., Karmakar, P.G., Tiwari, S.P., Joshi, O.P., Mohan, Y. (2004): Identification key for soybean (Glycine max) varieties released or notified in India. - Indian Journal of Agricultural Sciences, 74: 2158.

\section{How to cite this article:}

Dhaliwal, I., G. Khosla, T.P. Singh, B.S. Gill and Kaushik, P. 2020. DUS Characterization of some Released Varieties and Advanced Breeding Lines of Soybean (Glycine max L.) under Punjab Agroclimatic Conditions. Int.J.Curr.Microbiol.App.Sci. 9(08): 2124-2135. doi: https://doi.org/10.20546/ijcmas.2020.908.242 